\title{
Bridging the gap: preparing the next generation of brain scientists to communicate with the general public and
} lawmakers

\author{
Saurav D. Singh ${ }^{1}$ and Hilary A. Marusak (D) ${ }^{1,2,3 凶}$ \\ (c) The Author(s), under exclusive licence to American College of Neuropsychopharmacology 2021
}

Neuropsychopharmacology (2021) 46:2233-2234; https://doi.org/10.1038/s41386-021-01084-5

A large portion of science is a public good (i.e., taxpayer funded) and trust and understanding of science and medicine is critical for society to reap the benefits of scientific advancements. Yet, national surveys demonstrate that only $38 \%$ have trust in scientists to do what is right for the public (Fig. 1a). The coronavirus disease 2019 pandemic has highlighted inadequacies in science communication (SciComm) that have long plagued the scientific community. Today, these inadequacies have been laid bare by the profound misunderstanding and mistrust of science among the public and lawmakers and can have serious consequences: for example, poor adherence with medical treatments or public health mandates.

One reason for the rift between scientists and non-scientists is that SciComm is not typically a formal part of scientific training at any level. For example, only three out of the top ten U.S. neuroscience $\mathrm{PhD}$ programs have elective courses or seminars in SciComm. None have required courses (Fig. 1b). Further, science training typically involves learning how to communicate within disciplines. This creates a cycle of communication style that is passed on from student to future mentor, which stifles cross-disciplinary collaboration and limits potential scientific impact. Importantly, cross-disciplinary research around neuroscience, in particular, has rapidly increased in recent years [1], which provides an opportunity for the American College of Neuropsychopharmacology and other neuroscientific organizations to lead the scientific community in cross-disciplinary research and communication. A recent National Academy of Sciences workshop highlighted the need to encourage team science and to transform neuroscience training to address challenges related to diversity, equity, and well-being [2].

A lack of formal SciComm training also limits the ability for sciencebased information to reach the public and affect decision-making at many levels, including policymaking. There are opportunities for SciComm, policy, and advocacy training through, for example, the Society for Neuroscience, the American Association for the Advancement of Science, and the National Science Policy Network. There are also several grassroot efforts for community engagement, such as local school-based programs or Brain Awareness Week events. However, these opportunities must be sought out by students and scientists and are not typically embedded in curricula. The widespread assumption that better SciComm will lead to improve societal outcomes has some empirical support, e.g. [3]. However, more research is needed to examine the best methods for improving SciComm and to measure the impact on societal outcomes, including policy decisions [4].

It is clear that, overall, more training is needed to effectively equip scientists to communicate with those outside their discipline, the general public, and lawmakers. So how do we train students and scientists to communicate effectively with a wide audience? Here we provide some general recommendations, with examples derived from our own experience developing and implementing a science policy group designed to improve SciComm and advocacy skills among students and scientists.

Institutions that are charged with training the next generation of scientists and clinicians can integrate SciComm into graduate and undergraduate curricula. Although communication is considered a core competency for undergraduate science majors and medical students, we advocate for standardized cross-disciplinary SciComm courses for all students. This foundational knowledge may improve science literacy among eventual members of the public and equip them to make more informed decisions. At the graduate level, students become increasingly specialized and the need to practice communicating science to those outside their own discipline becomes even more critical. Further, most students rely on informal SciComm training received through their mentor(s), which may to lead to unequal communication skills among trainees and limit scientific impact and career success. SciComm skills are also essential to cultivate among medical trainees, as effective patient-physician communication can improve patient outcomes [5].

Universities and professional organizations can also provide SciComm and advocacy opportunities for students, faculty, and staff. For example, institutions may provide seminars, workshops, advocacy activities, training programs, and fellowship opportunities. These opportunities are important given that most graduates of biomedical training programs go on to pursue careers outside of academia [6], including careers in SciComm or policy. Scientific organizations may also provide training opportunities for members to engage in SciComm and policy on a national or international level.

\footnotetext{
${ }^{1}$ Department of Psychiatry and Behavioral Neurosciences, Wayne State University School of Medicine, Detroit, MI, USA. ${ }^{2}$ Merrill Palmer Skillman Institute for Child and Family Development, Wayne State University, Detroit, MI, USA. ${ }^{3}$ Translational Neuroscience PhD Program, Wayne State University School of Medicine, Detroit, MI, USA. 凶email: hmarusak@med.wayne.edu
} 

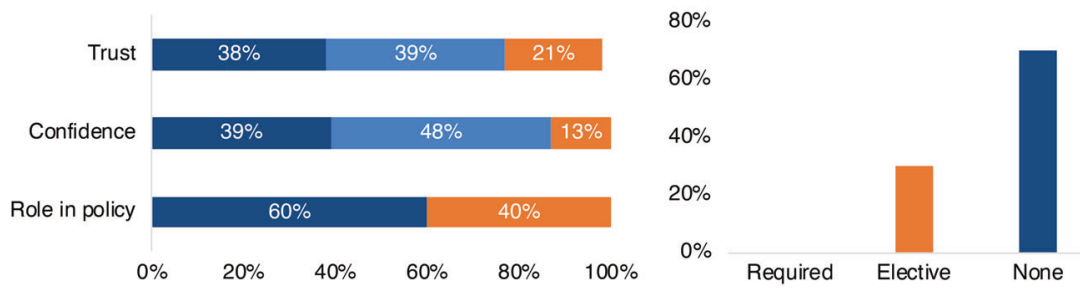

Fig. 1 Lack of public trust in scientists and lack of formal science communication training among Neuroscience programs. a US adults' opinions on scientists in 2020. Data are from the Pew Research Center [9]. b Science communication courses in the top 10 U.S. Neuroscience Ph.D. programs in 2020. Data are from the U.S. News and World Report [10].

SciComm training should also occur outside the classroom. Opportunities to practice communicating with the public and lawmakers are crucial for solidifying skills. Graduate students can teach younger students (e.g., K-12) and foster early interest in pursuing science careers through science/health fairs, student-run clinics, classroom visits, and outreach events. Laboratory tours, seminars, or "meet a scientist" events that are open to the general public and lawmakers provide opportunities for interaction. Scientists should be trained in sensitivity when interacting with diverse populations and should be prepared to deliver accurate scientific information that is tailored to the specific audience (e.g., media, classroom, legislators). Importantly, the burden should not completely be on scientists to address this issue. Public science education curricula, even at young ages, should be prioritized. The public can also be actively involved in scientific discoveries through, for example, community-engaged research or "citizen science," which may improve knowledge and scientific literacy and empower citizens [7].

There is a clear demand for science and science-based information on social media. Indeed, science-related pages on Facebook draw millions of followers, with the top 30 pages including prominent science communicators and organizations [8]. However, some of the top 30 pages may offer "questionable" or even "pseudoscientific advice or information." At the same time, the past decade has witnessed an increase in the proliferation of misinformation and anti-science information that shows no indication of slowing. While social media provides an unprecedented opportunity for scientists to combat misinformation and reach a wide audience, the proportionally small online presence of scientists and science-based information is a missed opportunity. To address this, SciComm and public engagementincluding social media-should be valued and rewarded. Time constraints and lack of incentivization are major barriers for scientists to engage in SciComm activities (e.g., social media, outreach, training). Professional organizations, funding agencies, promotion and awards committees, and other scientific institutions should value SciComm and engagement in order to motivate scientists to spend time in training and action.

To bridge the gap between scientists and non-scientists, we believe that SciComm must be a formal part of scientific training at all levels and must occur both inside and outside of the classroom. Further, with an ever-evolving communication landscape, scientists and institutions must incentivize public engagement and embrace social media. Making SciComm a priority may have widespread benefits, such as improving individual career outcomes, facilitating scientific progress, improved trust in science and medicine, and more evidence-based policies. The public will also be more equipped to make more informed decisions, which may lead to better public health outcomes.

\section{FUNDING AND DISCLOSURE}

S.D.S. and H.A.M. are co-founders of Science Policy NetworkDetroit (www.scipoldetroit.org). H.A.M. is supported by NIH/NIMH
K01 MH119241. The funders had no role in this manuscript. The authors declare no conflict of interest.

\section{REFERENCES}

1. Xu R, Ghaffarzadegan N. Neuroscience bridging scientific disciplines in health: who builds the bridge, who pays for it? Scientometrics. 2018. https://doi.org/ 10.1007/s11192-018-2887-3.

2. National Academies of Sciences, Engineering, and Medicine, Health and Medicine Division, Board on Health Sciences Policy, Forum on Neuroscience and Nervous System Disorders, Bain L, Posey Norris SM, et al. Evolving the culture of science and training in neuroscience to meet a changing world. In Proceedings of a Workshop in Brief. Washington, DC: National Academies Press; 2021. https://doi. org/10.17226/26176.

3. Webb AB, Fetsch CR, Israe E, Roman CM, Encarnación CH, Zacks JM, et al. Training scientists in a science center improves science communication to the public. Am J Physiol Adv Physiol Educ. 2012. https://doi.org/10.1152/advan.00088.2010.

4. National Academies of Sciences, Engineering and Medicine. Communicating science effectively: a research agenda. Washington, DC: National Academies Press (US); 2017.

5. Boissy A, Windover AK, Bokar D, Karafa M, Neuendorf K, Frankel RM, et al. Communication skills training for physicians improves patient satisfaction. J Gen Intern Med. 2016. https://doi.org/10.1007/s11606-016-3597-2.

6. Meyers FJ, Mathur A, Fuhrmann CN, O'Brien TC, Wefes I, Labosky PA, et al. The origin and implementation of the Broadening Experiences in Scientific Training programs: an NIH common fund initiative. FASEB J. 2016;30:507-14.

7. Turrini T, Dörler D, Richter A, Heigl F, Bonn A. The threefold potential of environmental citizen science - generating knowledge, creating learning opportunities and enabling civic participation. Biol Conserv. 2018. https://doi.org/10.1016/j. biocon.2018.03.024.

8. Hitlin BYP, Olmstead K. The science people see on social media: science-related Facebook pages draw millions of followers but feature more posts with 'news you can use' or ads than scientific discoveries. Pew Research Center. 2021. https://www.pewresearch.org/science/2018/03/21/the-science-people-see-onsocial-media/. Accessed 14 Apr 2021.

9. Funk C, Kennedy B, Johnson C. Trust in medical scientists has grown in U.S., but mainly among democrats. Pew Research Center. 2020. https://www.pewresearch. org/science/2020/05/21/trust-in-medical-scientists-has-grown-in-u-s-but-mainlyamong-democrats/. Accessed 1 Apr 2021.

10. USNews.com. Best global universities for neuroscience and behavior in the United States. US News World Report, LP. 2021. https://www.usnews.com/ education/best-global-universities/neuroscience-behavior. Accessed 14 Apr 2021.

\section{AUTHOR CONTRIBUTIONS}

S.D.S. and H.A.M. both wrote the manuscript.

\section{ADDITIONAL INFORMATION}

Correspondence and requests for materials should be addressed to H.A.M.

Reprints and permission information is available at http://www.nature.com/ reprints

Publisher's note Springer Nature remains neutral with regard to jurisdictional claims in published maps and institutional affiliations. 